\title{
Apologies as Politeness Strategies Expressed by Characters in "Revolutionary Road" Movie
}

\author{
Elham Abedi \\ English Department, Faculty of Humanities, Najafabad Branch, Islamic Azad University, Najafabad, Isfahan,Iran \\ Farinaz Shirani Bidabadi \\ Iranian Academic Center for Education, Culture, and Research, IUT Branch (ACECR), Isfahan, Iran \\ Hadi Salehi (Corresponding author) \\ English Department, Faculty of Humanities, Najafabad Branch, Islamic Azad University, Najafabad, Isfahan, Iran \\ E-mail: hadisalehi1358@yahoo.com
}

\author{
Received: 27-05-2016 \\ Accepted: 02-08-2016 \\ Advance Access Published: September 2016 \\ Published: 01-11-2016 \\ doi:10.7575/aiac.ijalel.v.5n.6p.134 \\ URL: http://dx.doi.org/10.7575/aiac.ijalel.v.5n.6p.134
}

\begin{abstract}
This research aimed to investigate kinds of offences that motivate the characters in the movie "Revolutionary Road" to deliver their apology and to describe the way the characters express their apologies. The study used Trosborg's apology strategies and Holmes' social dimensions of communication and kinds of offences finding, Hymes' ethnography of communication with SPEAKING formula. The data of the research were taken from apology expressions employed in the movie entitled "Revolutionary Road". The corpus included the sentences containing apology expressions following an offence, and other supporting expressions employed by the characters in the movie "Revolutionary Road". The dialogues containing apology expressions and the types of offenses from the apology expressions were transcribed. The result showed that the kinds of offenses were infringement on space, infringement on talk, infringement on time, infringement on possession and social behavior offence. The characters in the movie "Revolutionary Road" expressed their apologies with the simple and complex form of apology strategies both directly and indirectly. They also delivered their apologies in high tone and low tone. They also showed nonverbal expressions in apologizing. The apology strategies were influenced by the degree of severity of the offence and the response given by the addressee. The employing of apology strategy in apologizing was influenced by the social distance, the formality of the situation, and the social status of the participants. It is implied that the speech act of apology in different contexts including movies should be regarded and considered by sociolinguistics.
\end{abstract}

Keywords: Sociolinguistics, Speech act theory, Apology, Revolutionary road

\section{Introduction}

Language is used in community. "The language is used by people in different situations has always been the center of focus for sociologists and sociolinguists" (Mills, 2003, p.6). Sociolinguistics has so far been defined in different ways. Chaklader (1990) believes that sociolinguistics concentrates its study upon the social patterns in language usage. Hudson defines sociolinguistics as "the study of language in relation to society" (1996, p.4). Hymes in Chaklader (1990, p. 2) states that the term sociolinguistic is the correlations between languages and societies, and between particular linguistic and social phenomena. Furthermore, Trudgill in Chaklader (1990) states that sociolinguistics is a part of linguistics which is related to language as a social and cultural phenomenon. A section of sociolinguistics deals with speech acts. Speech act deals with actions in an utterance. Austin (1962, as cited in Levinson, 1983, p. 236) states that in uttering a sentence performing actions may be the center of focus. Mey (1993, p.110) also states that speech act is "words that do things". In other words, act in speech act theory refers to the action that is performed in making utterances. Thus, Yule (1996b, p. 53) classifies speech act into five types of general functions namely, "declarations (those kinds of speech acts that change the world via their utterance), representatives (those kinds of speech acts that state what the speaker believes to be the case or not), expressive (those kinds of speech acts that state what the speaker feels), directives (those kinds of speech acts that speakers use to get someone else to do something), and commissives (those kinds of speech acts that speakers use to commit themselves to some future actions)".

To this end, this study analyzed apology which belongs to expressive illocutionary act. The goal of speech act of apology is to keep desirable relationship between participants. Olsthain and Cohen (in Wolfson and Judd, 1983, p. 20) state that the act of apologizing occurs when some behaviors violates social norms. People need to apologize to express their regret for undesirable action in the past. In apologizing, people apply certain strategies of apology. Different circumstances related to the behavior may cause the different strategy of apology. In addition, this study aimed to 
consider apology as a politeness strategy. Politeness is very important to show that the speaker cares about others' feeling. Politeness is the expression of the speakers' intention to mitigate face threats carried by certain face threatening acts toward another (Mills, 2003, p.6).

Politeness can be defined as the means employed to show awareness of another person's face. Mills (2003) states that face is divided into two different classes: positive and negative. A person's positive face is the need to be accepted by others. A person's negative face is the need to be independent, and not to be imposed by others. Negative politeness is a face saving act which emphasizes the importance of the other's time or concerns, and even include apology for the imposition or interruption (Yule, 1996b, p. 61). Based on the definition of politeness above, the apology is a politeness strategy which has the effect of paying attention to the addressee's negative face (Coates and Cameron, 1988, p. 30). Holmes (1992) considers apology as a speech act directed to the addressee's face needs and intended to remedy an offense for which the speaker takes responsibility.

Apology is a politeness strategy in which the addressee's face is paid attention to. Related to the explanation above, it was interesting to analyze the act of apology in the film entitled "Revolutionary Road". Therefore, this study aimed to find out the act of apology in the movie entitled "Revolutionary Road". In fact, due to the variety in the context of the movie under study, this research was designed. Furthermore, sometimes in the context of movies, the interlocutors can convey different concepts directly and this can be a good source for language learners to master their pragmatic competence. The purpose of speech act of apology is to maintain good relationship between participants, and people need to apologize to express their regret for the past actions. Thus, for language learners it is important to know how people keep the relationship in their interactions in an unreal context. In apologizing, partners employ certain apology strategies. The amount of severity in action may also cause different strategies of apology. However, to understand the message in communication, we should consider the context. Therefore, the participants need to consider the context in which a certain speech act is performed. A speech act may happen in different social contexts. In fact, the way people talk is affected by the social context in which they are talking, and to whom they are speaking. The same message may be expressed very differently to different people. We use different styles in different social contexts. The context of movie is different from real life. In performing the speech act of apology certain social factors have been considered to account for the variety in strategies. The factors are the participants, the setting or the social contexts of the interactions, the topic or what is being talked about, and the function why are they speaking. In communicating, the speakers are expected to adjust the words they use with the situation where they speak. In the present study it was intended to find out how different characters adjust their verbal behavior with the unreal contexts of movie in performing the speech act of apology.

\subsection{Research questions}

1. What are different offences that need apologies employed by characters in "Revolutionary Road" movie?

2. How do the characters express their apologies in the movie entitled "Revolutionary Road"?

\section{Literature Review}

According to Olsthain and Cohen (in Wolfson, 1983, p. 22) there are five strategies for apologizing. First, an expression of an apology in which the speaker uses a word, expression, or sentence which contains a verb, such as: 'sorry', 'excuse', 'forgive', or 'apologize' to apologize. An expression of an apology can be reinforced whenever the apologizer feels the need to do so. Such reinforcement is usually accomplished by adding intensifiers, such as: 'really' or 'very'. For example, the expression 'I'm really sorry'. Second, the acknowledgment of responsibility in which the offender recognizes his/her fault. The degree of such recognition on the part of the apologizer can be placed on a scale. The highest level of intensity is an acceptance of the blame: 'It's my fault'. At a lower level an expression of self-deficiency is used: 'I was confused', 'I didn't see', 'you are right'. At another level the expression of lack of intent is used: 'I didn't mean to'. Implicit expression of responsibility is used as the next step. I was sure I had given you the right directions'. Finally, the apologizer may not accept the blame at all, which leads to a denial of responsibility: 'It wasn't my fault', or even blaming of the hearer: 'It's your own fault'.

Third, an explanation or account of the situation in which the speaker describes the situation which causes him/her to commit the offense which is used by the speaker as an indirect way of apologizing. In some cultures, this way of apologizing may be a more acceptable way of apologizing than in others. Fourth, an offer of repair in which the apologizer makes a suggestion to provide payment for some kind of damage she/he has caused. For instance, if someone is late for an appointment with a friend, he/she might say something like: 'How can I make it up to you, why don't I buy you lunch on Friday?' or someone who fails to fulfill an appointment might say: 'Would you be willing to reschedule the meeting?' and the last category is a promise of forbearance in which the apologizer commits himself/herself not to have the offense happen again. In most cases just one of the formulas is sufficient in order to perform an apology. But, often two or three formulas are combined together to create higher intensity of apology. What follows is a look at some studies conducted on various aspects of apology (Olsthain and Cohen (in Wolfson, 1983). In addition, Nureddeen (2008) conducted a study on apology strategies in Sudanese Arabic to determine the type and extent of use of apology strategies in Sudanese Arabic and focused on the sociocultural values of the Sudanese community. The results suggested that apology strategies are universal; however, type of apology strategies used differ from culture to culture. Moreover, Chamani and Zareipur (2010) investigated the use of apology strategies, and also the offenses that motivated apologies among native speakers of British English and Persian. The data were collected from real-life situations. Results showed that both English and Persian speakers used relatively similar apology strategies, 
with different preferences. Also, Al-Zumor (2011), in his study on apologies in Arabic and English, investigated English apology strategies used by Arab learners of English in India. He concluded that English speakers and Arabic speakers assign different degrees of severity to the same situation which is attributed to cultural differences.

In another study which was conducted by Jebahi (2011) on the use of apology strategies in Tunisian Arabic, it was found that the participants tended to use a statement of remorse in three main situations: when the person being offended is old in age, a close friend or having power that might affect the future of the person who committed the offense.

\subsection{Movie Theory}

Movie is an entertainment medium which cannot be separated from society. The production of movie is closely related to society. Movie makers live in the same society as their addressees. Allen and Gomery (1985, p.158) stated that "in fictional movies, characters are given attitudes, gestures, motivations, and appearances that are, in part at least, based on social roles, and on general notions about how a policeman, factory worker, debutante, mother, or husband is 'supposed' to act". Therefore, it can be concluded that a movie is a reflection of social life. "Revolutionary Road" is a movie which shows the American dream disturbed by a nightmare. It took place in the 1950s. It is about a young couple who meet at a party, get married and create a suburban life with a nice house, "modern" furniture, two kids, housework for the wife, and cigarettes, boredom and desperation for both of them. The researcher focused on the movie 'Revolutionary Road' to investigate different strategies of apology used in this movie. Different theories and different media were used in analyzing the apology strategy. First, the researcher classified the kinds of offences motivating the characters to express their apologies. Second, this research investigated the way the characters expressed their apology, and the forms of apology strategy applied by them. Because the media of the research was a movie the way the characters express the apologies could be seen through the tone and non-verbal expressions that supported the act of apologizing in the movie entitled 'Revolutionary Road'.

\subsection{Synopsis of the Movie Under Study}

A couple named Wheelers who lived with their two children on Revolutionary Road in a wealthy Connecticut countryside are introduced at the beginning of this movie. The first impression is that Wheelers are suffering individual inadequacies: April Wheeler (Kate Winslet) is a housewife who wishes to be an actress. Frank Wheeler (Leonardo DeCaprio) doesn't want to continue his occupation. Both April and Frank are trying to get rid of their unhappiness and change their lives in different ways. For instance, April joins a theatre group, and Frank, starts an affair with a secretary, which provides only temporary relief of the unhappiness. In order to relieve the situation, April suggests that they move to Paris to start a new life. She says that she can take up a job in a foreign agency. April starts to pack the house for a new future. It seems that everyone is facing a kind of dissatisfaction in his/her life; however, they get along with this unhappiness differently. Another couple who were friends with Wheelers are Shep (David Harbour) and Milly (Kathryn Hahn), who have experienced a similar course as Frank and April. Shep wishes to live with April whom he loves. Milly believes that there is no other option, and this way satisfies her. The only character who looks to be free of the confinement of disappointment is John Givings, the Wheeler's real-estate agent' son who sold them their home on "Revolutionary Road". It's impossible to watch "Revolutionary Road" and not compare it with your own life. Moving from Paris for April and Frank is not a time for Frank to escape his job and for April to escape the confines of home, but it is a chance to make a new life. The beauty of this movie is its ability to offer hope. Finally, real estate agent sells the house on Revolutionary Road to another young couple, and this shows us that we can escape this cycle in our own lives. In life people have to make the decision to either follow unknown world or accept each day as it comes. This movie was chosen due to the situations in the movie for which the characters had to apologize.

\section{Methodology}

The recent research is a descriptive qualitative research. The researcher uses the movie "Revolutionary Road" as the source of data. The data of the research were taken from the verbal and non-verbal apology expressions. The verbal apology is the apology uttered by the characters while, non-verbal expressions are the expressions shown by the speakers to support their apology. They are: body language, facial expression, smile, eye contact, and touching. The intonation in expressing apologies is also used to support the data. The samples of this research are the sentences containing apology expressions following an offence, and other supporting expressions (body language, facial expression, smiles, eye contact and touching), and also the intonation in uttering the apology expressions employed by the characters in the film entitled "Revolutionary Road".

\subsection{Instrument}

A set of television and DVD player, and the VCD of the movie entitled "Revolutionary Road" were used in this study. Also, the transcript of the movie from the internet: (http:/ /simply Leonardo dicaprio. Com/content/scripts/Revolutionary Road. pdf) extracted in order to conduct a more comprehensive analysis on the apology strategies. Then the movie 'Revolutionary Road' was to be played several times in order to achieve the aim. After that the transcription of the dialogues containing apology expressions from the movie was used to explore types of offenses from the apology expressions in the movie.

\subsection{Data Collection}

The steps followed in collecting the data of the research are: First, finding the transcript of the movie from the internet: (http://simply Leonardo dicaprio. Com/content/scripts/Revolutionary Road. pdf ), Second, watching the movie 
"Revolutionary Road" several times using a set of DVD player and television, Third, transcribing the dialogues containing apology expressions from the film as the data, Fourth, identifying the types of offenses from the apology expressions transcribed, Fifth, identifying the apology strategies from the apology expressions transcribed, and Sixth, giving codes on each datum. For the sake of reliability of the gathered data, the kinds of offences which motivate the characters to apologize, the way the characters express their apologies, and why the characters use the way to express their apologies were ranked by the researchers as well as a PhD candidate in Teaching English as a Foreign Language (TEFL). The validity of the gathered data was also checked by an expert in the field of English teaching.

\subsection{Data Coding}

To make the classification and the analysis of the data easier, at first, the researcher counted the number of each datum. Then, the researcher identified the number of the CD (CD I or CD II) in which the apology expressions were employed by the characters in the movie. The types of offenses motivating the characters to apologize which were found in the movie and written in capital letters: It should be noted that this classification was adopted from Soesilowati (2009) and included: a) Infringement on space (SPA); b) Infringement on talk (TALK); c) Infringement on time (TIME); d) Infringement on possession (POS); e) Social behavior offences (SOB), and f) Instance of inconvenience (INC). The apology strategies were classified as Expression of regret (Regr); Request for forgiveness (Forg); Acknowledgment (Ack); Expression of lack of intent (Lint); Expressing concern for hearer (Conc); Expression of embarrassment (Emb); Explanation (Expl); Minimizing the degree of the offence (Min); Explicit acceptance of the blame (Accp); Promise of forbearance (Forb); Offer of apology (Apol); Blaming someone else (Blam), and Expression of self-deficiency (Self), for example, Datum 4/ II / TALK / Apo. Accp = It is the datum number 7 which was found in CD I in the movie. The offence that motivated the speaker to apologize is infringement on time. The speaker conveyed an expression of regret and blaming someone else strategy to express apology.

\subsection{Data Analysis}

After collecting the data, the researcher classified the apology expressions expressed by the characters in the movie "Revolutionary Road" based on types of offences found by Holmes (1992). Then, the researcher described the context of the conversation which involved the situational context of the conversation, the participants of the conversation, and the participants' relationship when the apology expression employed by considering Holmes' (1992) social dimensions of communication. As the next step, the researcher analyzed the ways the characters expressed their apology based on Trosborg's apology strategies. Then, the tone and other non-verbal expressions were applied by the characters in apologizing were identified. Finally, the researcher analyzed why the characters used such ways to express their apology by considering Hymes' Ethnography of Communication with SPEAKING formula.

\section{Results}

The results of the movie analysis revealed 22 data which contained apology expressions. Six kinds of offences were found including: social behavior offence, infringement on possession infringement on talk, infringement on time, instance of inconvenience, and infringement on space. These offences motivate the characters in the movie "Revolutionary Road" to express the act of apologizing. The details of the data based on the classification of the offences are as follows: Social behavior offence: three cases; Infringement on space: two cases; Infringement on possession: two cases; Infringement on time: one case; Infringement on talk: five cases.

\subsection{Social Behavior Offence}

Social behavior offence is an offence relating to someone's attitude or behavior to the addressee. It can be an act which can embarrass the speaker himself/herself. Sometimes, it can be a way of behaving which can make the hearer get angry to the speaker. It can also be an impolite behavior done by the speaker to the hearer. There are three data which belong to this kind of offence. For instance, in a case, the conversation takes place beside Shep's motorcycle. The participants of the conversation are April and Shep. April is drunk at that time. When she wanted to get onto Shep's motorcycle, suddenly she rolls over from Shep's motorcycle. Because of the accident, Shep decided to leave his motorcycle and asked April to continue their journey on foot. After April bumps into a man who is hurriedly walking with his couple, she walks into Shep's motorcycle. Because she is drunk at that time, she rolls over from Shep's motorcycle when she wants to get into it. Because of the incident, Shep decides to leave his motorcycle, and asks April to continue their journey on foot. Hearing Shep's statement, April realized that it was because of her behavior. She agreed with Ben's (another character in the movie) idea. But, she also expressed her apology to Shep for the offence she expressed. It belongs to social behavior offence since she apologizes for an act which embarrasses the addresser herself.

April was drunk, so she only applied a simple form of apology strategy to apologize. She uttered an expression of regret "Sorry" to apologize. She expressed her apology in a relaxed manner because she was drunk at that time. When she made a mistake she immediately expressed her apology to show that she was a polite person. Hence, she expressed her apology to Shep although she was drunk at the moment. April uses negative politeness as her apology expression indicates her awareness of having impinged on Shep's negative face. They have an intimate relationship. The situation of the conversation is informal. Those factors influence Shep in responding April's apology. Moreover, Shep knew that April was drunk at that time. Thus he responded to April's apology positively. Then they continue their journey on foot.

\subsection{Infringement on Space}

Infringement on space is an offence in which the speaker's act may restrict other peoples' space, for example, it may be the case when someone jumps in a queue, without considering the right of the people standing in line. In two cases, this 
type of action was found. For instance in a case, the conversation took place in a building where a music concert was held. Frank and April were talking enthusiastically. Unintentionally, Frank bumps a man who was taking some pictures around the building where the music concert was held. Their social status was the same, since they didn't know each other. For example, Frank: "April, I am so excited. I feel so free". April: "You are going to love it". (Frank bumps into a man) Frank: "Sorry. Sorry". The man: "Excuse me".

This offence belonged to infringement on space because the speaker arrowed the hearer's space by her act. Frank used expressions of regret in apologizing. He said "Sorry" twice. He applied simple form of apology to apologize since he bumps him unintentionally, and they had the same social status. He uttered the first "sorry" in a high tone then he said the second one in a low tone. The high tone indicated that he bumps him unintentionally. It also shows that he startled with the offence he made. The low tone indicated that he really regrets his behavior toward him. He expressed his apology in a serious manner while smiling. It also functions to lessen the degree of severity on the offence he made. He used negative politeness as he performed an apology after he recognized and felt regretful to it. His apology showed that he is a polite person. He expressed his apology although he bumps him unintentionally. Therefore, his apology expression implies that he is reluctant to impinge on the addressee. However, Frank succeeded in apologizing. The man responded to his apology positively by giving Frank his smile. The man did not regard it as a serious problem. Moreover, he said "Excuse me" to frank. It indicated that he considered that the incident might be also caused by his position. At that time, he was standing in the middle of the road.

\subsection{Infringement on possession}

Infringement on possession is an offence which occurs when there is damage on someone's possession. It can be an act done by the speaker who damages or causes the hearer's personal property lost. It can also be an act which is intentionally done by the speaker relating to the hearer's personal property. The speaker damaged the hearer's face by his/her act. For example, the conversation took place on a bridge. The participants of the conversation were: April, and Boze. April who was walking along the bridge at that time unintentionally met Boze. He was playing Bungee Jumping. Boze stole her purse. April then asked Boze about her purse because she really needed some money at that time. April: "Boze?.. Boze". Boze: "Look. My reasons were noble". April: "I trusted you”. Boze: "I needed the scratch. What can I say? Please forgive". April was very startled when she saw Boze on the bridge. She immediately called his name. Boze who got ready to go Bungee Jumping was very surprised to see her there. He never expected to meet April again after he stole her purse. He apologized April as he made an offending act toward April. The offence made by Boze belonged to infringement on possession. Thus, it is an infringement on possession because he stole April's property, namely her purse.

Boze used a complex form of apology strategy in apologizing. At first, he employed an explanation "My reasons were noble. I needed the scratch. What can I say?" By employing this strategy, he tried to explain his reason of stealing April's purse. After giving his explanation, he uttered a request for forgiveness "Please forgive". He expressed himself in a tremble and fast voice. His fast voice indicated that he was shocked to meet April in that place, while his tremble voice showed his fear. He uttered his apologies in a low tone to show that actually he was not a rude man. He was forced in doing that offence because he really needed the money in April's purse to have fun. Bozz applied negative politeness in apologizing. It is negative politeness because he apologized to recover the addressee's negative face. The relationship between the participants also influenced the way the speaker uttered his apologies. Thus, they have the same social status as they are friends. They also have a close relationship. That is why, although he was afraid of April, he tried to be relaxed in apologizing. At first, April got annoyed because of Boze's act. But, when she saw his funny manner, she smiles. April responds to his apologies positively. It can be seen from their relationship which remains close after Boze says his apologies to April.

\subsection{Infringement on Time}

Infringement on time is an offence which occurs when the offender does not come at the agreed or proper time. The speaker wastes the hearer's time by his/her behaviour. Hence, the speaker loses the hearer's negative face by his/her behavior. To this point, the participants of the conversation are April, Mr. and Mrs. Givings and Gabrielle. April and her parents were standing in the museum hall to welcome their guests. April was waiting for Gabrielle, her best friend. After waiting for a long time, Gabrielle arrived Gabrielle: "April”. April : "Gabrielle! How are you?" Gabrielle : "Good. I'm sorry I am late... but the guards outside took turns to search me”. The datum above showed that the apology was expressed by Gabrielle. Gabrielle called April when she arrived there. April was very happy to see her, they hugged one another. Gabrielle then expressed her apology to April because she was late. She apologized for the offence she made toward April. It is an infringement on time because she made April waste her time to wait for her. Gabrielle expressed her apologies in a complex form of apology expressions. She combined an expression of regret "I'm sorry I am late" with blaming someone else strategy "but the guards outside took turns to search me" in apologizing. She expressed her apologies in a low tone and a serious manner. The serious manner in apologizing indicated that she really regretted her coming late. It also indicated that she was really sorry to make April wait for her. The low tone showed her modesty in apologizing. It also indicated her reluctance to impinge on the hearer's negative face. She used a complex form of apology expression to express her deep regret and to explain that her coming late was caused by other people. Through the strategy of blaming someone else, she wanted to tell April that it is caused by the strict inspection done by the security guards in the museum. She applied those strategies of apology to maintain their social harmony. Her apologies indicated her acknowledgement of her committed act. Gabrielle used negative politeness in apologizing since it showd her awareness of having impinged on the hearer's negative face. They have the same 
social status as they are best friends. They have an intimate relationship. It makes the conversation go on good atmosphere. April responded to Gabrielle's apologies positively. April smiled at Gabrielle when Gabrielle apologized to her. Her smile indicated that she did not regard her coming late as a serious problem.

\subsection{Infringement on talk}

Infringement on talk is an offence relating to the speaker's statement which may damage or lose the hearer's face. The speaker may say a wrong statement or he/she may say something which insults the hearer's feeling with his/her words. The examples of infringement on talk are interrupting, talking too much, saying the wrong thing, etc. What follows are examples of this kind. The conversation took place in a house attic. The participants of the conversation were Frank, April and Michael. To pass the time, Weiss tried to tease Morales. Morales knew that Weiss tried to tease her. She tried to change the topic of the conversation. She said that Weiss always called a woman he loved with her last name. Weiss quickly corrected it by calling her first name, Cynthia. But it turned out that Morales did not like to be called with her first name. Frank: "Isn't this romantic? Almost like we're on a date, isn't it, Gabrielle?" Jennifer" Yeah, right. You on a last name basis with most of your girlfriends?" Frank: "Jennifer". Jennifer: "Please, don't. Just don't".

Frank: "I know. I know, it didn't feel right. Sorry”. Frank was interested in Jennifer and tried to tease her. Jennifer responded to him by saying that Frank always calls a woman he loves with her last name. Hearing that, Frank quickly corrected his words. He called Jennifer with her first name. However, Jennifer felt that it was not a right thing to be called with her first name. Then, she asked him not to call her with her first name again. It is because calling someone with his/her first name indicated an intimacy whereas their relationship at that time was only as colleague. Realizing his fault, Frank quickly apologized to Jennifer for the offence he made. This offence belongs to infringement on talk. It is an infringement on talk because the speaker annoy the hearer.

Frank expressed his apology by applying a complex form of apology. He combined an explicit acceptance of the blame "I know. I know, it didn't feel right", followed by an expression of regret "Sorry" to apologize. He expressed his apologies in a low tone and a soft voice. It indicated that he was a polite man as he apologized in a polite manner. The employing of both indirect and direct apologies showed the seriousness of the speaker in regretting his fault. Frank used negative politeness as it signaled his awareness of having impinged on the hearer's negative face. Their social status is the same. They also have an intimate relationship. It makes the conversation go on good atmosphere. Besides apologizing verbally, Frank also used non-verbal expressions. He also smiles to her. It indicated that the offence he made toward Jennifer was only to tease her. Frank responded to Jennifer's apologies positively. She realized that Jennifer's offending act toward her is caused by her behavior too. Indirectly, she asked him to call her in that way. Her positive response could also be seen from their relationship which was still in harmony after the apology expressions delivered by Jennifer.

\section{Conclusion \& Discussion}

The kinds of offenses that motivated the characters in the movie "Revolutionary Road" to offer their apologies were infringement on space, infringement on talk, infringement on time, infringement on possession, and social behavior offence. The characters in the movie Revolutionary Road" expressed their apologies in various ways. It is concluded that the characters in the movie "Revolutionary Road" used simple and complex form of apology strategies to express their apologies. A simple form of apology strategy used one apology strategy, while a complex form of apology strategy employed more than one apology strategy in apologizing.

Furthermore, it is concluded the speakers chose a simple form of apology strategy to apologize if the offence was not very serious, and the addressee responded to their apologies positively. The speakers applied a complex form of apology strategy when the offence they did was very serious and the hearer responded to their first apology negatively. However, the hearer still gave a chance to the speakers to utter their other apology expressions. Therefore, the speakers employed a complex form of apology strategy to repair their relationship with the hearer after the offence. The speakers who had a close relationship with the hearer and the situation was informal preferred to choose direct apology, especially the expression of regret in apologizing.

Whereas, if the speakers had the same social status and a close relationship with the hearer the situation would be formal, the speakers tended to apply indirect apology or a more formal direct apology, namely a request for forgiveness. However, there is a datum which shows that in informal situation, the same social status and an intimate relationship, the speaker employs indirect apology, namely an explanation strategy. It is because the speaker feels that the offence he make is caused by the other people. Thus, it is concluded that if the speaker is superior, the relationship between the participants is distant, the situation is informal, and the speaker chooses direct apology.

The interlocutors in the movie under investigation expressed their apologies in high tone and low tone. The high tone indicates that the speaker does his/her offending act unintentionally. The speaker also applies high tone when he/she feels that the offence she has done is not so serious. Low tone is employed by the speakers to calm down the hearer. In apologizing, the characters apply low tone with various voices. Low tone with soft voice indicates that the speaker is not an impolite person. Low tone with firm voice is used to show the speaker's seriousness in apologizing. Besides uttering verbal expressions of apology, the characters also show nonverbal expressions in apologizing.

The findings of this study are in line with the study by Indrawati (2003) in which she investigated the speech act of apology in the Novel "The Picture of Dorian Gray". Similar to the present paper, Indrawati (2003) used Trosborg's theory of apology strategies. Like the present research in that study it was found that first, the characters in the novel "The Picture of Dorian Gray" use two forms of apology strategy, namely, direct and indirect forms of apology strategy, 
and direct strategy is mostly employed by the characters. Second, the characters in the novel use complex and simple strategy of apology, and the most apologizing strategy used are complex strategy. Third, the choice of apologizing strategy by the characters is strongly influenced by the degree of severity of the offence. The above study has to do with the researcher study. Indrawati's (2003) study motivated the researcher to study more deeply about speech act of apology in the film "revolutionary Road". Here the researcher uses different theory and different media in analyzing the apology strategy. The researcher only employs Anna Trosborg's theory of apology strategy. The media used is a film. First, the researcher classifies the kinds of offences motivating the characters express their apologies. Second, this research involves the way the characters to express their apology, and the forms of apology strategy applied by them. Because the media of the research is a film, the way the characters express the apologies can be observed through the tone and nonverbal expressions that support the act of apologizing.

\section{Implications of the Study}

This study focused on the apology strategies used by the characters in the movie "revolutionary road"; therefore, the results can be of use for several groups. First, language teachers who can take advantage of the results, and through the obtained results, they can enhance language learners' pragmatic competence. Teachers can teach the language learners how the speech act of apology is used in real situations. Furthermore, material developers can make use of the results of the present study, and include those excerpts of real use of apology strategies in their English language teaching materials such as textbooks at schools and universities. In Iranian EFL context, there is not constant access to real instances of communication; therefore, studies like this can provide more comprehensible and authentic input as stated by scholars in the field like Krashen (1982).

\section{References}

Allen, R. C. \& Gomery, D. (1985). Film History: Theory and Practice. New York: McGrawHill.

Al-Zumor, A. W. Q. G. (2011). Apologies in Arabic and English: An inter-language and cross-cultural study. Journal of King Saud University-Languages and Translation, 23(1), 19-28.

Chaklader, S. (1990). Sociolinguistics: A Guide to Language Problems in India. India: Mittal

Publications.

Chamani, F.\& Zareipur, P. (2010) A Cross-Cultural Study of Apologies in British English and Persian. Concentric: Studies in Linguistics 36(1), 133-153

Fahmi, R., \& Fahmi, R. (2006). Apology strategies of Jordanian EFL university students. Journal of Pragmatics, 38 , 1901-1927.

Holmes, J. (1992). An Introduction to Sociolinguistics. UK: Longman Group Ltd.

Indrawati, E. (2003). The Analysis of The Act of Apologizing in Oscar Wilde's "The Picture of Dorian Gray". Surakarta: Sebelas Maret University.

Jebahi, K. (2011). Tunisian university students ${ }^{\text {ee }}$ choice of apology strategies in a discourse completion task. Journal of Pragmatics, 43(2), 648-662.

Levinson, S. C. (1983). Pragmatics. New York: Cambridge University Press.

Mey, J. L. (1993). Pragmatics: An Introduction. UK: Blackwell Publishers.

Mills, S. (2003). Gender and Politeness. UK: Cambridge University Press.

Nureddeen, F. A. (2008). Cross cultural pragmatics: Apology strategies in Sudanese Arabic. Journal of Pragmatics, 40(2), 279-306.

Wolfson, N. \& Judd, E. (1983). Sociolinguistics and Language Acquisition. Rowley: Newbury House Publishers, Inc.

Yule, G. (1996b). Pragmatics. Oxford: Oxford University Press. 